\title{
The Unique Challenges for Creative Small Businesses Seeking Feedback on Social Media
}

\author{
YASMINE KOTTURI, Carnegie Mellon University, USA \\ ALLIE BLAISING, California Polytechnic State University, USA \\ SARAH E. FOX, Carnegie Mellon University, USA \\ CHINMAY KULKARNI, Carnegie Mellon University, USA
}

\begin{abstract}
Social media can be an effective source of feedback on open-ended work, such as product design. Unlike large businesses with entire teams dedicated to "social," little is understood about how small business owners-constrained both in personnel and resources-leverage the benefits of direct, informal communication channels afforded by social media. Drawing on a series of design workshops and interviews with 26 small business owners at a local feminist makerspace, we report on the unique challenges small business owners experience when seeking feedback on open-ended work via social media. We found participants carefully balanced large-scale access to diverse audiences with attempts to receive reliable feedback, and they often targeted audiences narrowly to reinstate control and build trust. In addition, the small business owners in our workshop idealized building authentic relationships with their social audiences to create collectively. To do so successfully, participants detailed the extensive behind-the-scenes work required of them such as navigating blurred personal and business identities and the self-regulation necessary to continuously stay engaged and not internalize discouraging feedback.
\end{abstract}

CCS Concepts: • Human-centered computing $\rightarrow$ Human computer interaction (HCI); HCI design and evaluation methods.

Additional Key Words and Phrases: online feedback exchange; social media; online community; design feedback; creative entrepreneurship; social commerce; product development

\section{ACM Reference Format:}

Yasmine Kotturi, Allie Blaising, Sarah E. Fox, and Chinmay Kulkarni. 2021. The Unique Challenges for Creative Small Businesses Seeking Feedback on Social Media. Proc. ACM Hum.-Comput. Interact. 5, CSCW1, Article 15 (April 2021), 27 pages. https://doi.org/10.1145/3449089

\section{INTRODUCTION}

Social media can be an effective source of feedback for individuals engaged in open-ended work, such as product design $[53,75]$. This is because social media-websites and applications that enable users to create and share content and participate in conversations with others [13]-provide valuable access to vast, diverse audiences. Indeed, many large businesses have successfully leveraged social media's direct, informal communication channels to large-scale audiences for early product feedback and co-creation. For instance, the beauty company Glossier and the prescription glasses retailer Warby Parker are often attributed as early adopters of social media's unique affordances to uncover

Authors' addresses: Yasmine Kotturi, ykotturi@cs.cmu.edu, Carnegie Mellon University, 5000 Forbes Avenue, Pittsburgh, PA, USA, 15213; Allie Blaising, California Polytechnic State University, San Luis Obispo, USA; Sarah E. Fox, Carnegie Mellon University, 5000 Forbes Avenue, Pittsburgh, PA, USA, 15213; Chinmay Kulkarni, Carnegie Mellon University, 5000 Forbes Avenue, Pittsburgh, PA, USA, 15213.

This work is licensed under a Creative Commons Attribution International 4.0 License.

(C) 2021 Copyright held by the owner/author(s).

2573-0142/2021/4-ART15. https://doi.org/10.1145/3449089

Proc. ACM Hum.-Comput. Interact., Vol. 5, No. CSCW1, Article 15. Publication date: April 2021. 
needs and improve their products. Glossier CEO and founder Emily Weiss recently credited their billion dollar valuation to simply "listening to [her] customers" via social media channels throughout the product development process [8].

However, unlike large businesses with entire teams dedicated to "social" [25], there is little understanding of how small business owners, who are constrained both in personnel and resources, can leverage the benefits of social media. Indeed, prior work suggests that creative small businesses may face challenges in using social media for feedback, from cognitive fixation to nonexistent platform support. To begin, creative small business owners often start businesses as "expert amateurs" [46]. That is, these small business owners often see themselves as creators, and possess some expertise in their craft. Yet, as they lack formal training in general design practices, seeking feedback on open-ended work via social media can be counterintuitive, especially when feedback pertains to design fixation: the inability to see alternative design solutions beyond the present artifact [31, 46].

Moreover, social media platforms themselves introduce challenges for small business owners given nonexistent support for seeking feedback. Unlike other online communities geared towards supporting feedback exchange [18, 23, 39], social media platforms are not explicitly designed to help users ask for feedback on open-ended work. For example, they do not scaffold responses to include both critical and positive feedback [42] like specialized feedback communities do. Finally, for small business owners and entrepreneurs who lack access to financial resources and social capital, succeeding in social commerce is challenging, and requires "additional labor" [11]. This additional labor can include the added time and effort required of small business owners to identify, modulate, and market a fused brand identity (of the self and the business).

These barriers to successfully seeking design feedback on social media disproportionately affect minority groups in entrepreneurship, such as women [20], who are more likely to be engaging in "side hustles" to make ends meet [35]. For instance, in 2019, $87 \%$ of the 2.4 million active sellers on Etsy.com, a global online marketplace for creative small business owners, identified as women [1-3]. With the increased uncertainty introduced in labor markets through taskification [27], as well as the proliferation of online marketplaces, this necessity-driven entrepreneurship is expected to continue to rise [35].

Therefore, in this paper, we examine the lack of resources available to small business owners and creators while seeking design feedback on social media platforms, the role these technological platforms play in their feedback seeking practices, and the additional labor this social innovation work represents. In doing so, we focus on two central research questions:

(1) What practices do creative small business owners develop in seeking feedback on open-ended work via social media?

(2) What conceptual, technological, and emotional challenges do they face when seeking feedback on open-ended work via social media?

In investigating these questions, we seek to inform the design of robust online feedback tools that more readily take into account users' perspectives. This approach directly responds to Foong et al.'s recent call to understand the unique challenges of seeking feedback [23]. We specifically focus on those underrepresented in entrepreneurship, such as women [61]. Doing so allows for deeper nuance to emerge in understanding the value of social feedback. As noted by Zhu et al., such a situated understanding of social feedback is a critical missing link in feedback researchers' understanding of the value of different types of feedback [78].

We report on two design workshops and a set of interviews with 26 local small business owners at a locally-owned feminist makerspace. We leverage the format of the design workshop to both shed light on the two research objectives above and to inform a longer term participatory design process. Through this workshop, we charted how participants sought feedback on social media 
throughout their product design and development processes and the associated challenges they experienced.

These workshops revealed three key findings for how the small business owners in our workshops used social media for feedback along themes of scale, interpersonal relationships, and self-regulation First, rather than tapping into large-scale audiences available on social media (a feature that is often important to mid-to-large sized companies), the resource-constrained small business owners in our workshops actively worked to narrow their feedback audience. For example, participants created or joined private direct message groups with loyal customers, peers, or mentors to solicit feedback. Second, because their social media audiences were composed of both personal and business connections, feedback was most useful when the asker and giver had both a shared context and a trusting relationship. For instance, a useful shared context was that of small business ownership, and trust was facilitated by an agreement to keep ideas confidential and ensure a sense of psychological safety. Third, unlike large companies that have separate teams dedicated to "social" and creative processes, engaging social media audiences in production processes called for a nearly invisible process of self-regulation. For example, participants described the internal work it took for them to regain their confidence after receiving discouraging feedback. This work was magnified because of the blurring of participants' personal and business identities. To small business owners who were already balancing the work of small business management, feedback seeking and self-regulation often felt like an additional labor too heavy to take on alone.

We situate these findings by noting that participants were often sole proprietors, juggling multiple lines of work, and trying to make ends meet through the commercialization of their creative work. This paper seeks to enrich existing online feedback exchange literature with both practical and conceptual contributions for supporting a wide range of feedback-seeking practices Towards practicality, our findings suggest that large-scale and diverse feedback audiences $[48,70]$ are neither accessible nor always desirable for small business owners who are operating under many constraints. Conceptually, this paper highlights the importance of the dynamic relationship between feedback giver and receiver for successful feedback. It pushes beyond static categories of peers, friends, or family as used in previous work [75]. Instead, our work suggests that as a field, we should examine ever changing aspects of such relationships, such as how trust shifts among feedback givers and receivers. Finally, this paper illustrates in detail the self-regulation practices that are often demanded of small business owners seeking and managing feedback on social media, because of the tight interplay between their own identities and that of their small business.

\section{BACKGROUND AND RELATED WORK}

The ideas and literature that inform our work draw from mainly three bodies of scholarship: the importance of feedback on open-ended work, the prevalence of online feedback exchange, and the growing relevancy of social feedback online. We situate the importance of this scholarship in labor market trends: people are increasingly likely to engage in work away from traditional organizations and often participate in creative endeavors as sole proprietors. We examine feedback practices specifically within the context of these new forms of work in a wide array of online environments (e.g., creative online communities, social media, crowd platforms, and forums).

\subsection{The Broader Context: Social Media and Labor}

Seated center-stage at the 2017 Female Founders Conference, Emily Weiss, CEO of the cosmetics startup Glossier, announced "The most innovative thing we do is listen to our customers." In Weiss's telling, when she pivoted towards product development, looking first to her fans for feedback and advice seemed only natural. Weiss's followers vetoed particular lipstick shades, offered early thoughts on naming and ingredients and, according to Weiss, contributed to the making of a beauty

Proc. ACM Hum.-Comput. Interact., Vol. 5, No. CSCW1, Article 15. Publication date: April 2021. 
company "much more co-created" than any of its predecessors. With $\$ 100$ million in annual revenue in 2019 from just 36 beauty products, Glossier and its "social-selling" techniques have captured the eager attention of business communities across sectors [60].

Glossier may have been an early innovator in its use of "social" to engage large and diverse audiences to co-create their products by asking for feedback, but many more companies have since learned how to leverage such direct communication channels with customers. As such, social media is increasingly associated with "social product innovation," where social media platforms are seen as a way to boost authentic, meaningful engagement among customers and between customers and companies $[25,60]$.

And while success stories like Glossier are appealing and suggest new modes of commercial innovation, they gloss over the work that it takes to ask for and receive feedback on projects under development through social media. For example, Weiss and the Glossier team occupy a rare position of elevated social status and access to capital that makes seeking outside engagement with partial products and implementing quick changes to their designs a relatively manageable endeavor. Yet, small business owners who focus on open-ended work and other creative practitioners across levels of expertise engage in similar practices every day without nearly the same level of support, resources, or capital.

For example, as of 2019, the online marketplace Etsy.com hosted 2.4 million "active sellers" around the globe who self-identify as creative small business owners or micro-entrepreneurs and sell handmade and vintage goods through the platform $[1,3]$. This diverse group of creative practitioners comprises individuals who are often juggling multiple lines of work, lack formal design training ("expert amateurs" [46]), and are without the support and security of traditional organizations [35]. In addition to their entrepreneurial endeavors, they must safeguard their work from being used sans permission by larger companies. (In one unfortunate example, the giant retail company Forever21 repeatedly used and profited off of small business owners' drawings for apparel designs, and did so without their permission [4].)

Despite these challenges, these creative practitioners are increasingly interested in exploiting their innovation's commercial potential. As of 2019, nearly 1 in 3 Americans are reported to be engaged in some form of a "side hustle" [7]. For many, this is less of a hobbyist practice than it is an effort to make ends meet. Avle, Hui, and colleagues described the material and social challenges facing those seeking to "self-entrepreneurial-ize," where self-upgrading, maintaining software and hardware, and overcoming exclusion all act as barriers to livelihood [11]. However, the ability to monetize oneself (in the case of influencers) or one's creative practice to the point of subsistence is extremely infrequent (e.g., 8\% of bloggers earn enough to support themselves [20]). This leads communication scholar Duffy to deem these efforts as "aspirational labor" [20], or the reconciliation of the tensions between labor and leisure, authenticity and self-promotion, and creativity and commerce.

In these entrepreneurial settings, we see high levels of uncertainty and little institutional support, which in turn has propelled independent workers to leverage social media [35]. As Duffy described, the appeal of social media platforms is the potential to boost one's visibility and the promise of professional advancement [20]. But how one might use social media to self-entrepreneurial-ize is often unclear, particularly for those from under-resourced communities, with less regular access to technical resources or social capital [33]. In this paper, we investigate how the use of social media, that has successfully served as a source of feedback and success for large companies, may be of service to those attempting to self-entrepreneurial-ize. By investigating feedback perceptions and behaviors among small business owners and creators on social media, we seek to better understand how to support sole proprietors engaged in online feedback exchange. 
We are especially interested in the use of social media by small business owners who are often underrepresented in accounts of entrepreneurship [15]. For example, women comprise a rapidly growing proportion of this nascent workforce (e.g. 87\% of Etsy's 2.4 million active sellers identify as women [1]), but are nearly invisible in mainstream discussions of entrepreneurship. For those who are underrepresented in entrepreneurship, recent Human-Computer Interaction (HCI) scholarship has highlighted the importance of receiving positive and high quality feedback, as it boosts entrepreneurial self-efficacy [19]. (This informed our choice of a feminist makerspace as the study site.)

\subsection{Benefits of Feedback for Open-Ended Work and Technological Feedback Support}

Feedback can be described as reactions to a person's performance of a task or work product, which is then used as a basis for improving future performance [31]. Receiving feedback on open-ended work can be the differentiating factor between a successful idea and a failed one, as feedback often uncovers what a creator has overlooked without awareness (the gap between intended and actual interpretation) and catalyzes reflection [31]. The reflective practice feedback sparks-the practice by which professionals become aware of their implicit knowledge base and learn from their experience-can foster higher self-efficacy [64]. Moreover, receiving feedback on open-ended work can improve the creator's overall output quality as it promotes iteration [14]. In addition to the benefits of receiving feedback, simply giving feedback can be useful as it also strengthens the giver's reflective practice $[47,58]$. To maximize these benefits, substantial research has explored what constitutes effective feedback: equal parts critical and positive [38, 57], actionable, and justified [42].

Recent HCI research has introduced various software systems that support beneficial feedback exchange for open-ended work. In general, these online environments provide creative practitioners with feedback from a distributed network of individuals [23]. In much of this research, feedback comes from online crowdsourcing: the practice of obtaining information from a large number of people via the Internet for a monetary fee [34, 36, 72]. Xu et al., for instance, systematized seeking feedback from a crowd of paid micro-task workers to help university students improve their visual designs [71]. As compared to design experts, online crowds have been found to be an effective way to increase the scale of feedback generated [49].

In addition to crowd workers, other distributed networks of individuals include other creative practitioners or even general admirers who provide feedback in existing online creative communities such as Behance or WEBook. In one study, Xu and Bailey conducted a large-scale analysis of an online "crit" community called PhotoSIG, which provided templates to guide feedback exchange, such as a way to share one's work visually and enable other users to leave responses on how the creator might improve their photography [70]. The authors found that as long as the critiques were of high quality, online critiques did improve work quality, even when they lacked the subtle messaging and signaling of in-person interaction. As a result, research in online feedback exchange primarily focused on improving the quality of feedback given [34, 36, 49, 72]. Thus, aspects of feedback exchange remain under investigated, such as how to ask for feedback effectively online [17] or how to implement feedback received online [76].

More recently, Foong et al. argued that the HCI community's focus on improvements to solely feedback generation is misplaced and symptomatic of a larger lack of understanding and formalization of end-to-end "online feedback exchange" [23]. Foong et al. argue that a comprehensive understanding online feedback exchange is critical for developing a successful socio-technical system for online feedback [23]. Therefore, they present a framework with five key parts needed to successfully acquire effective feedback online, starting with the creator's decision to ask for feedback and then formulating the feedback request. In this paper, we directly build on this work 
by investigating the challenges experienced by those asking for feedback on social media, focusing particularly on the overlooked experiences of small business owners.

\subsection{The Growing Importance of Social Feedback}

Despite the importance of social media platforms in creative work such as product design [46, 68, 75], research on the actual practices of creative practitioners using social networking sites for feedback on their designs and products is rare [23]. The few notable (and recent) exceptions offer evidence that the feedback that creative practitioners gather from social media on their open-ended work can be of high quality. For instance, Yen et al. reported feedback generated by design students' social media followers was the highest quality relative to cost, compared to feedback generated by paid crowd workers and an online design community [75]. In addition, Marlow and Dabbish highlighted how the social transparency afforded on social networking sites yielded better feedback on open-ended work by encouraging reciprocity [53]. Lastly, Zhu et al. applied Feedback Intervention Theory ( [40]) to understand the effects of "social" feedback along with three other types of feedback-negative, positive, and directive-on following task performance [77, 78]. They found these differing feedback types effected task performance by improving motivation (in the case of social feedback).

While this prior work showed initial signs that social feedback can be of high quality, little is known about how people seek feedback on social media [75]. Participants in the experimental studies described above (e.g. [78]) were required to use the same protocol across online communities and feedback types in order to control for extraneous variables (i.e., they were not allowed to formulate their questions in their own way). But the quality of feedback solicitation impacts the quality of feedback generated [10], and therefore how people ask for feedback on social media warrants an independent analysis [23]. More generally, since much of this work has been experimental and quantitative, researchers have therefore called for qualitative work to investigate the different perceptions of social feedback [78].

Furthermore, existing studies often collapse social media platforms among other types of "crowd" platforms [74], lumping together in experimental design social media platforms such as Facebook with crowdsourcing platforms like Amazon Mechanical Turk. We argue that studying social media platforms independently is necessary given key differences between crowd and social platforms. In particular, social media audiences have different compositions and styles of engagement, and these differences influence feedback exchange (e.g., how to successfully request feedback from an audience mixed with personal and business relations). Such an analysis is especially valuable for small business owners who often leverage, even rely on, their personal social media accounts to represent their business or creative practice [20]. Thus, their social media followings are often a melting pot of personal connections (e.g., friends, family, peers) and business-oriented connections (e.g., potential customers, collaborators, competitors). These relationships may make feedback seeking more reliable as people are more likely to respond to requests on social media when they know the requester, as compared to strangers [13]. We investigate how small business owners seek feedback on social media from audiences mixed with personal and business relations, as well as how the type of relationships-friend, family, peer, customer, admirer, and stranger-affect business owners' feedback seeking behaviors.

In addition to the diversity of feedback audiences on social media, the extensive research on general information and help seeking on social media platforms ( [21, 29, 52, 55]) further supports a need to study feedback seeking on social media independent from other online communities. This research notes, for instance, that the customizable visibility settings, or "broadcast levels" on social media that change scale and exclusivity of audiences are important to question askers [59]. Choices about whether a post can be made public and accessible to anyone on the Internet (i.e., public feeds, streams, or forums) or only to select users (i.e., private feeds, direct message channels, or closed

Proc. ACM Hum.-Comput. Interact., Vol. 5, No. CSCW1, Article 15. Publication date: April 2021. 
groups [13,59], impacts both the questions that people ask and how information is processed by the question asker [22]. Given the increased diversity of communication channels on social media, this paper investigates how broadcast levels impact the informational and social value of responses.

Note that while information-seeking via social media Q\&A might be seen as feedback exchange [70], there are critical differences between the two. For instance, feedback is a specific kind of information given by an agent to a target with the goal of improving the object or its performance [40]. So while research on social media Q\&A may suggest that entrepreneurs turn to social networking platforms to find trustworthy information (e.g., where to purchase needed materials and learn about valuable tech support tools) [68], question answering does not necessarily have this performance or quality improvement intent. Therefore, these social media activities-Q\&A and feedback exchange-warrant independent analyses. In this paper, we focus on the latter.

\section{METHODS}

Foong et al. call for methods which increasingly take into account users' perspectives when building tools to support online feedback exchange, in order to increase researchers' awareness of the processes' socio-psychological factors that have been historically overlooked (e.g., anxiety induced by asking for feedback) [23]. Zhu et al. specifically call to deploy qualitative methods to better understand social feedback in particular [78]. Therefore, we build upon previous work in HCI which leverages design workshops as a way to begin a process of co-creation of tools which lie at the intersection of users' and researchers' expertise.

\subsection{Design Workshop Site and Participants}

We developed and facilitated two workshops (12 participants in the first workshop) with a total of 22 people (ages 25-54) at the feminist makerspace "Prototype PGH". Founded in 2016, Prototype PGH's mission is to build gender and racial equity in tech and entrepreneurship by "providing affordable access to high tech tools and equipment, offering workshops that prioritize the experiences of marginalized communities, and cultivating a professional support network" [9]. The makerspace has two locations in Pittsburgh's Oakland and Homewood neighborhoods. The first is dedicated primarily to co-working and the second serves as a machine shop and event space. The makerspace hosts regular workshops on technical skills such as laser cutting, 3D printing, and pattern-making, as well as special programs on topics like body affirming tailoring and plant medicine. Prototype PGH also serves as a hub for local entrepreneurs, through informal meetups and the Women's incubator program.

3.1.1 Workshop Site and Recruitment. We chose to collaborate with Prototype PGH for three key reasons. First, since its founding in 2016, the makerspace's team members have spent five years building strong relationships with local creative practitioners. These connections greatly aided in our efforts to reach out to those engaged in independent creative practice. Second, the makerspace's ethos-that "everything is a prototype"-aligned with that of the workshop and our motivation to facilitate feedback throughout the design process (from early-stage inception of an idea to market-ready products). Third, the first author has been actively involved with the space for almost four years (attending functions and workshops) and is a due-paying member starting in February 2019; she utilized the space's co-working hours and mingled with members in a casual setting. This relationship helped establish rapport with its community members, as well as offered an opportunity to better understand the culture of the space-one dedicated to dismantling systems of discrimination within traditional sites of tech and engineering.

Both workshops were held in August 2019, one in the morning on a weekend day and the other during the evening on a weekday. These times were selected in collaboration with Prototype PGH 
leadership, in order to ensure that the most number of people would be able to join (avoiding times when organizers knew people might likely be performing waged or caring labor). The space was wheelchair accessible, had ample parking, and was close to public transit stops. Pre-made preferred pronouns stickers were provided to encourage a gender inclusive environment.

To aid in recruitment, the first author created digital flyers to be distributed via the makerspace's listserv and social media accounts, as well as relevant small business and crafting groups on social media. Following guidelines the makerspace's leadership provided, we clearly communicated it was a paid workshop and child care was provided. In order to avoid unintentionally dissuading those who may not view themselves as "creatives", we left out domain-specific jargon like "formative feedback solicitations." Instead, we simply used "feedback". The second author also created paper flyers and traversed the city to post with permission on bulletin boards in coffee shops. Each workshop lasted 150 minutes and participants were compensated $\$ 25$ for their participation.

3.1.2 Participants. Most participants were previously familiar with the site either because they were members or because they had passed by the space on their commutes. To participate, workshop attendees were expected to take part in a creative small business or be interested in monetizing their hobbyist craft (e.g., jewelry making, sewing, pottery, poetry). 21 workshop participants were women and 1 attendee was non-binary. We encouraged participants to invite their friends and peers to join them at the workshop, which happened in two cases: one family member and one business co-owner. There were no restrictions based on primary income source, age, gender-identity, or craft type. These non-restrictions were important for two key reasons. First, the small business owners in our target audience vary in how central a role their business plays in their life (full-time gig, part-time side-hustle). Second, researchers' understandings of what constitutes "creative work" can be different than what creative practitioners themselves believe [24,27]. During recruitment, we avoided using terms like "designer" as this can inadvertently subvert those who find such a term off-putting as often associated with economic prestige [62]. Some participants self-identified as entrepreneurs, but almost all were sole proprietors of their business, except for two participants who were business partners. See Table 1 for participant demographics and social media usage. All names have been changed to protect the identities of participants.

\subsection{Design Workshop Structure and Activity}

During the two workshops, attendees engaged in a two-part exploration of their collective perceptions, challenges, and approaches to seeking feedback on social media.

3.2.1 Leading up to and Following the Workshop. Participants completed pre-workshop and postworkshop questionnaires. The pre-workshop questionnaire asked attendees to share demographic details, their product line, primary source of income, the social media platforms they regularly used, whether they had a formal background in the arts or design, the last time they used social media for soliciting feedback, as well as expectations, goals and questions regarding the workshop. We also asked participants about any involvement they had in seeking feedback online (beyond social media), and on how their solicitations across different platforms were similar or different. Not all participants were in the routine habit of seeking feedback on their social media, but each expressed a high interest in learning to do so. In the post-workshop questionnaire, participants were asked to share what they learned from the workshop, both from their peers and researchers, as well as to provide general feedback on the workshop using the "I like/I wish" exercise (used in prior design workshops [30]).

Leading up to the first workshop, the facilitation materials were circulated with the staff and organizers of the makerspace for feedback and refinement. Prior to the second workshop, the 
Table 1. Workshop and follow-up interview participant demographics. Note: all names have been changed to protect the identities of participants.

\begin{tabular}{|c|c|c|c|c|}
\hline Pseudonym & Pronouns & Small Business Category(ies) & Age & Social Media Usage \\
\hline Kim & She/her & Home \& Living & $35-44$ & WhatsApp \\
\hline Emily & She/her & Jewelry \& Accessories & $35-44$ & Facebook \\
\hline Jasmine & She/her & Clothing & $35-44$ & $\begin{array}{l}\text { Instagram, Facebook, } \\
\text { Youtube, Twitter }\end{array}$ \\
\hline Mia & She/her & Jewelry; Home \& Living; Production & $25-34$ & $\begin{array}{l}\text { Instagram, Facebook, } \\
\text { YouTube, Twitter }\end{array}$ \\
\hline Heather & She/her & Fiber Arts & $35-44$ & Instagram, Facebook \\
\hline Sarah & She/her & Pet Supplies & $35-44$ & Instagram, Facebook \\
\hline Aleaha & She/her & Jewelry; Home \& Living; & $25-34$ & $\begin{array}{l}\text { Instagram, Facebook, } \\
\text { Twitter }\end{array}$ \\
\hline Lily & She/her & Clothing & $55-64$ & Instagram, Facebook \\
\hline Riya & She/her & Art \& Collectibles & $25-34$ & Instagram, Facebook \\
\hline Miranda & She/her & Art \& Collectibles & $25-34$ & Instagram, Facebook \\
\hline Tricia & She/her & Clothing; Theatre Production & $25-34$ & Facebook \\
\hline Kristen & She/her & Makeup \& Skincare & $35-44$ & $\begin{array}{l}\text { Instagram, Facebook, } \\
\text { Pinterest, YouTube }\end{array}$ \\
\hline Lisa & She/her & Food \& Drink & $45-54$ & $\begin{array}{l}\text { Instagram, Facebook, } \\
\text { Twitter }\end{array}$ \\
\hline Haley & They/them & Theatre Production \& Education & $25-34$ & Facebook \\
\hline Mary & She/her & Art \& Collectibles & $45-54$ & Instagram, Facebook \\
\hline Andrea & She/they & Filmmaking \& Media Production & $25-34$ & $\begin{array}{l}\text { Instagram, Facebook, } \\
\text { YouTube }\end{array}$ \\
\hline Cindy & She/her & Home \& living; Food \& Drink & $45-54$ & Instagram, Facebook \\
\hline Tia & She/they & Poetry & $25-34$ & $\begin{array}{l}\text { Instagram, Facebook, } \\
\text { Twitter, Snapchat }\end{array}$ \\
\hline Lauren & She/her & Director of a makerspace & $35-44$ & $\begin{array}{l}\text { Instagram, Facebook, } \\
\text { Twitter }\end{array}$ \\
\hline Sierra & She/her & Jewelry \& Accessories; Bath \& Beauty & $35-44$ & Facebook \\
\hline Lola & She/her & Jewelry \& Accessories; Clothing & $25-34$ & $\begin{array}{l}\text { Instagram, } \\
\text { Facebook }\end{array}$ \\
\hline Beth & She/her & Bath \& Beauty & $25-34$ & $\begin{array}{l}\text { Instagram, } \\
\text { Facebook }\end{array}$ \\
\hline Natalie & She/her & Jewelry \& Accessories; Clothing & $25-34$ & $\begin{array}{l}\text { Instagram, } \\
\text { Facebook }\end{array}$ \\
\hline Trevor & $\mathrm{He} / \mathrm{him}$ & Glass Art & $25-34$ & $\begin{array}{l}\text { Instagram, } \\
\text { Facebook }\end{array}$ \\
\hline Jessica & She/her & Bags \& Purses & $35-44$ & $\begin{array}{l}\text { Instagram, } \\
\text { Facebook }\end{array}$ \\
\hline Richard & He/him & Arts \& Collectibles & $25-34$ & Instagram \\
\hline
\end{tabular}


researchers took into account feedback received from the first workshop's participants, and iterated on the workshop activities, as described in detail below.

3.2.2 Workshop Design. Design workshop activities were selected based on effective group sharing and ideation dynamics, as well as the underlying perspective that participants were experts. For the latter, we frequently communicated to workshop attendees that we were eager to learn from them and that the workshop was intended to be an opportunity for multi-directional knowledge transfer. For the former, we drew on the Think-Pair-Share methodology [50], which seeks to avoid "groupthink" by allowing for each participant to reflect individually after a prompt in a "think" phase before engaging in paired and group discussions. During the "pair" stage, each member partnered up with another person to share their individual reflections. Finally, the "share" stage involved participants engaging in group wide discussion, while facilitators aimed to make themes of the conversation salient and highlighted ideas that resonated across the group.

At the start of the workshop, participants were organized around three large workshop tables, with approximately four attendees per table. The initial exercise in both workshops was guided by the following prompts: "What challenges do you experience (or foresee) when soliciting feedback on social media?" "How have you been successful (and unsuccessful) in doing so?"

The second exercise differed between the first and second workshop, as we implemented feedback received from the first workshop participants. The first workshop featured a second exercise asking participants to create a physical artifact of an idea, take picture of it, and then post this picture on their social media to ask for feedback. This exercise aimed to help ground reflections on formative feedback seeking in practice. However, this exercise took up a sizable amount of participants' time, spent largely in isolation, and most participants already had clear conceptions of the challenges they experienced or anticipated when asking for feedback on social media. Therefore, for the second workshop, we removed this activity and instead included another Think-Pair-Share exercise which delved deeper into emergent themes around the importance of nuanced visibility settings for feedback requests and the diversity of feedback solicitation audiences. For example, to reflect on these themes in detail, we posed the following questions to attendees: "Where on social media do you ask for feedback;" "Who do you ask for feedback from on social media." Digressions from these questions during "Share" stage were welcomed and encouraged, in a continued effort to ensure the workshop was driven equally by participants.

3.2.3 Follow-up Interviews. During the month following the workshops, we interviewed four small business owners (thus, $\mathrm{N}=26$ ) who were interested in participating in the workshop, but could not join because the event conflicted with their schedules. These interviews focused on similar questions posed during the workshops (considerations for feedback solicitation audience and use of varied privacy settings of solicitations). Interviews also provided opportunities for questions more challenging to ask in a group setting. For instance, we asked interviewees to share examples of feedback solicitations on their social media. We also conducted two follow-up interviews with the co-founder of the makerspace. The goals of these interviews were three-fold: to engage in a broader reflection of the site's mission, to understand how the workshop series fit within that mission, and to receive feedback to be implemented in further collaborations such as during the participatory design of feedback technologies. Through these follow-up interviews, we were able to conduct a "member check" to ensure our syntheses was representative [65]. Interviews lasted 60 minutes, and were conducted remotely via Zoom (Zoom.com), except for the interview with the co-founder who we met in-person at the makerspace. Participants were compensated $\$ 10$ for an hour of their time. 


\subsection{Data Analysis and Positionality}

The research team captured audio (one recorder per workshop pair), video recordings (one camera per workshop), and took notes during the workshop. All audio recordings were transcribed in their entirety via an automated service (Temi.com) and reviewed for errors and typos by hand. We analyzed these data through a process of open coding to identify initial themes across the workshops. We later engaged in affinity diagramming [16] over the course of three weeks, where the first and second authors reviewed each transcript, marked sections that informed and extended this paper's two motivations, and printed out the corresponding raw data. Together, we formed clusters around key themes: challenges with soliciting feedback (lack of and need for control), feedback solicitation audience targeting (family, customers, peers), and other concerns (the fusion of personal and professional identities and the need for self-regulation). All authors repeatedly met during this period to review key findings and iteratively refined a set of analytic memos which expanded on themes emergent across our data.

3.3.1 Positionality. We disclose the identities and positionality of the researchers and authors of this paper, as a concern for reflexive design research practice and as a commitment to intersectionality [63]. The workshops were led by a research team composed of two white women from the West and Southeast regions of the United States, one white woman who is a U.S. immigrant from Canada, and a man who is a U.S. immigrant of Indian origin; all are cisgender, middle-class researchers working as faculty or pursuing postgraduate education at public and private institutions in the United States. Both workshop facilitators (the first and second author) engage in an open-ended side gig (dance and photography, respectively), and, while slightly younger than the average age of attendees, they were close in age to several workshop participants.

\section{FINDINGS}

\subsection{The Inaccessibility of Large-Scale Feeds on Social Media for Small Businesses Seeking Feedback, and Tactics to Overcome}

Our participants were initially attracted to social media for the large-scale and direct communication it offered with potential customers. The social media platforms participants described using for feedback included: Instagram, Facebook, SnapChat, WhatsApp, and Twitter (See Table 1). They hoped such platforms would allow them to build relationships, promote their work, and seek feedback. But many soon realized, as one-person operations juggling several lines of work, that these large-scale feeds (also known as large broadcast levels on social media [59]) were not accessible in terms of feedback seeking. In total, 17 of 26 participants discussed the inaccessibility of large-scale feeds on social media platforms. In the following sections, we describe several of their stories for why large-scale feeds were inaccessible, and tactics participants used to overcome this inaccessibility.

\subsubsection{Large-scale Feeds on Social Media were not Conducive to Building Trust Needed for Small} Business Owners Seeking Feedback. To begin, when it came to leveraging large public groups or followings on social media to garner feedback, participants repeatedly mentioned the difficulty of forming relationships on large-scale public Facebook groups, such as "Etsy Buyers and Sellers" with tens of thousands of members. For instance, Tia, a poet, directly attributed the large scale of an online group with a lack of trust: "Because the group is so large and not so intimate, you don't form those trusting relations with other members." Sierra, who made jewelry and handbags, took Tia's explanation a step further. She described how she and other small business owners she knew chose not to ask for feedback in these large public groups as signals of trustworthiness were hard to parse in large audiences. As Andrea, a filmmaker, highlighted, group size was often synonymous 


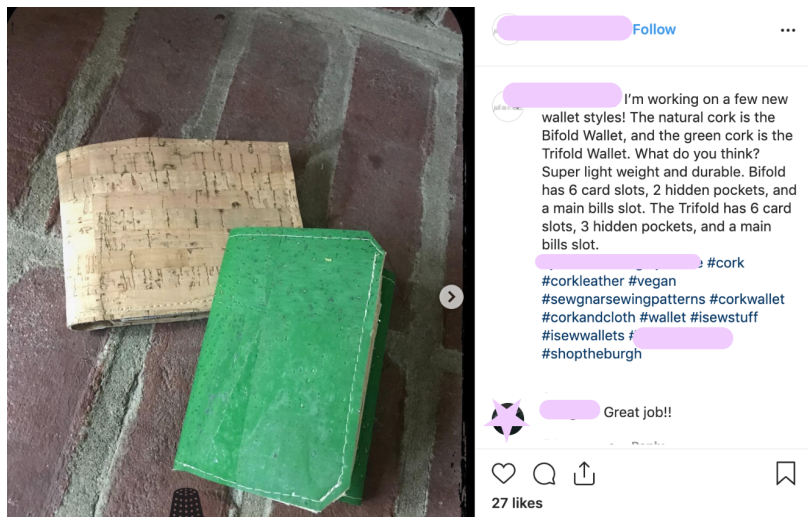

(a)

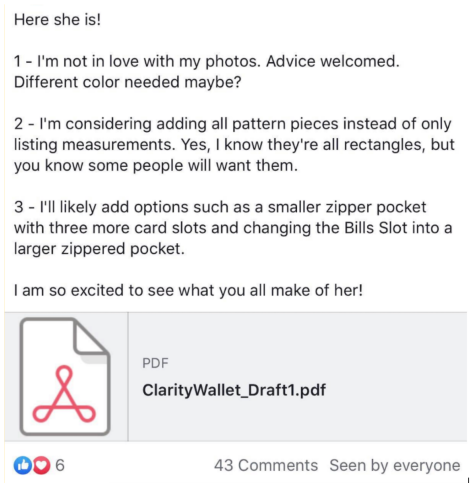

(b)

Fig. 1. Two of Jessica's requests for feedback on social media targeting different broadcast levels. Above (a), a feedback request to her followers on a public Instagram account. Below (b), a feedback request to her small (25 people) secret Facebook group of fellow sewers. Note the difference in fidelity of artifact in feedback request (high vs low, respectively). In her private group comprising those she trusted, Jessica described not needing to invest time to make her feedback request "engaging", as compared to her public request. Jessica explained that the groups' shared context of small business ownership and the small scale, as well as the lack of algorithmically controlled feeds, ensured maximal audience views.

with noise, noting when there are "too many people in the groups [...] you get a lot of inexperienced people wasting your time."

Similarly, Lauren reflected on asking for feedback from her social media following of just over one thousand people. She equated asking for feedback from this large audience to venturing into the abyss or, what she referred to as the entire Internet, given the public availability of her account: "My concern with going broad is that I'm essentially asking the Internet what they think...and I always take the Internet's feedback with a grain of salt because who I really care about is like the 12 people in this room [other small business owners].” For Lauren, asking for feedback from her followers meant taking into account perspectives which she did not want to prioritize. Already strapped for resources, Lauren had to ensure that the energy she spent towards asking for feedback was well allocated and focused on the perspectives of those she cared about most. This focused attention was 
essential for Lauren to ensure the next steps she took to inform her work were based on feedback from her target audience.

4.1.2 Large-Scale Feeds on Social Media Lacked Necessary Control for Small Business Owners. In addition to lack of trust, another reason why large-scale feeds on social media platforms offered limited feedback utility for participants was more mechanical: saturation of activity feeds. Due to the large scale nature of these feeds, many people were posting, and it was hard to have content be seen in the first place. Natalie, a fiber artist, reflected on leaving a large group of fellow small business owners because of what she saw as constant commercial activity not conducive to receiving meaningful feedback: "I was a member of a really big [crafting group], but I left it because it was too big to be helpful...It was meant to connect sellers to buyers. But it was mainly just sellers posting their items. Some of them did get feedback, but most of them didn't even get any views." Requests for feedback would often be lost among, or outbid by, all the other types of posts such as general product promotion or casual chatter.

Participants additionally mentioned how algorithms intended to make users' news feeds more engaging through personalization displayed content non-chronologically. Sierra noted that this non-chronological ranking led to fewer responses being timely, if any responses came in at all: "With the algorithms, when you do get people to respond, they do see later posts in your group...so maybe you'll get feedback from them later." Sierra found it difficult to receive feedback in a timely manner because she lacked the ability to control the visibility of her request in large-scale feeds. She emphasized this difficulty across different types of feeds on social media platforms: "I mean that's a challenge both when you have a following and groups, to me the following and the groups, I have the same issues." Here, Sierra pointed to the lack of chronological order of posts. Haley, a playwright and stand-up comedian, added on to highlight how this lack of chronology had further downstream effects as well. They noted trouble in parsing the resulting notifications of those responding to their questions, with product preferences or ideas: "It's hard to know who to give priority to, when [the notifications] come in. They are all out of sequential order." The downstream effect of non-chronological algorithmic ranking was that the corresponding notifications were similarly untimely. As chronology was how they determined priority and organized what felt chaotic, Haley was forced to manually check and monitor timestamps.

\subsubsection{Small Business Owners Targeted Audiences Narrowly on Social Media to Find Reliable Feedback.} The small business owners in our workshop learned that, to tap into the benefits of social media's direct communication channels with a diverse audience, they had to take it into their own hands and allocate their time into environments which they could more readily rely upon. For the small business owners at our workshop, this often meant forming new, or seeking out existing, small groups on social media platforms. For instance, these small social groups were formed as private, direct message channels, or "secret" and "closed" groups. In total, all but four participants (85\%) shared how a small-scale setting on their preferred social media platform provided a safe haven to find reliable feedback. These small groups were composed of friends, other small business owners, and vetted customers (i.e., customers who proved loyalty through continued purchases and support). For instance, Kim, who made decorative home products, shared how her small group of close friends served as a way to ask for feedback on in-progress work:

"You have to have a core group of people, you can't just go shout on the streets to everybody, 'Hey, what do you think about my idea?'...I have a group on WhatsApp of my friends."

Instead of shouting "on the streets" by asking for feedback in a large-scale feed, Kim emphasized the need for a "core group of people," which for her was a group of "eight to ten" friends who all had 
small business ventures. Kim's statement resonated with the other small business owners in the workshop and triggered a group-wide discussion on smaller scale audiences-which participants defined as generally less than 50-to serve as a means to garner reliable feedback.

The reliability of these small groups manifested in a few ways. For instance, almost as a direct response to reclaim control lost in large-scale feeds, participants discussed how it was easier to ensure the visibility of a feedback request. Tia noted, "When it's a smaller group it's easier for them to see it because sometimes when it's a big group [the feedback request] may even be overlooked because so many people are posting." Jessica, who made wallets and handbags, echoed this position, adding that she did not have to worry about her small groups' engagement with her feedback request:

"In the smaller groups, we're not worried about engagement at all. We just want the group members to see it, comment, and answer any questions we might have, see how we interpret a pattern a little bit differently, whether it's the materials we use or if we add something to it or embellish it in any way."

Jessica's preference to seek feedback in her small groups-comprising those who shared a similar creative domain and vetted customers-allowed her to focus on asking for feedback. This is because, as she described, there was no algorithm dictating the visibility of her post and she did not have to worry about making posts engaging to a diverse audience.

Posting to a small group resulted in a simple process that business owners could repeat reliably, almost a direct response to the lack of control participants felt in large-scale, algorithmicallycontrolled feeds on social media platforms. Participants were able to remember the backgrounds and the names of everyone in their small group, which in turn fostered trust. Lily, who made clothing, stated that she "found the smaller groups more supportive where everyone knows each other's name, what their business is," while Tia stated simply that small groups were more often composed of "people who you can trust." Such trust was important in order for participants to be able to set norms around asking for and giving feedback, such as preferences for more or less critical feedback. Knowing each other's names and businesses, for participants, was a good signal for trustworthiness.

In addition to being small, these preferred audiences were also often exclusive. For instance, participants described being a part of private direct message channels or groups formed on-platform. "I have a group, a private, 'Closed' group, for my business with my customers" noted Emily, who made jewelry. Having vetted, known audiences helped reduce participants' fears around asking for feedback, which they described as ordinarily being an anxiety-inducing endeavor. This was especially important when asking about feedback on unfinished products (See Figure 1). For instance, Kim explained how when it came to asking for feedback early on in her creative process, her small group of friends on social media was the place to go:

"It's never too early from your trusted sources. I have a group on WhatsApp with my friends, we've been friends for like 10-15 years, [and it's] just like 'steal my stuff!'. I just throw stuff out to them and I'm like, what do you guys think of this?"

Sharing unfinished products made participants more vulnerable to having ideas taken and replicated elsewhere without permission. Kim highlighted the level of trust found in her small group on WhatsApp, where she exposed her ideas without the worry that her friends would use her ideas without permission. As small business owners who were often only able to work on one project at a time, this threat of having one in-progress idea stolen was often synonymous to having their livelihood taken away. With precedent of having ideas stolen from other small business owners always lingering in participants' minds, this small scale and exclusivity helped them feel more in control. 


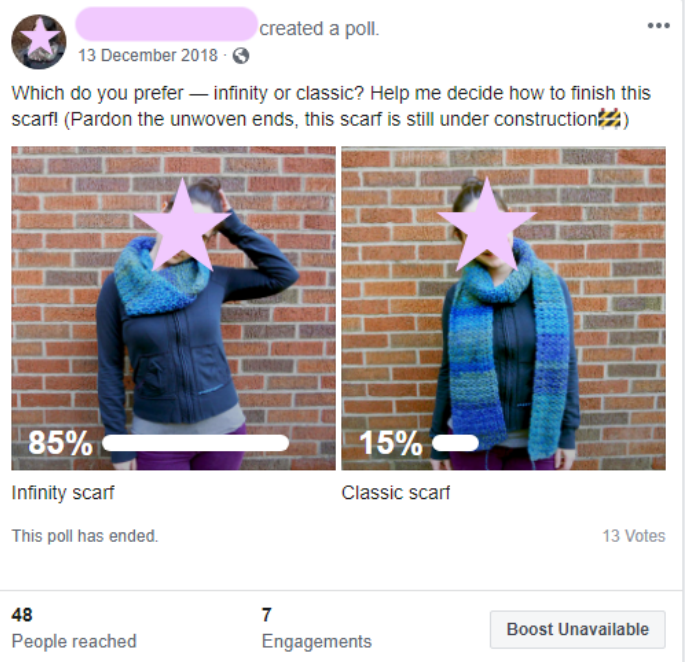

Fig. 2. Another example of a participant feedback request on social media

\subsection{Navigating Feedback Audiences Comprising Personal and Business Relations on Social Media}

Participants described having social media audiences composed of friends, family, other small business owners, potential customers, prior customers, general admirers, unknown individuals, and even bad actors. There was no one-size-fits-all approach when attempting to seek feedback from an audience of such diversity. Instead, participants reflected on both positive and negative experiences asking for feedback from each genre of audience (e.g. family, friends, customers, peers, and so on). For instance, when seeking feedback from personal connections (e.g., friends and family), Tia, a budding poet, found their family lacked the necessary context to understand the feedback request:

"People don't see your vision so they don't understand it, family or friends, they don't really care too much about [the business]. They're like, 'OK, I don't want to hear about that. It's not beneficial. It's not food." "

Tia's friends and family did not understand their shift away from sharing pictures of food to promoting their poetry. While Tia was exasperated by their family's lack of interest in their business endeavor, Jasmine, who made products to help those battling cancer, recounted how crucial her friends' and family's presence on social media was for offering motivation and formative feedback: "they did end up giving me some really great ideas about closures or what kind of material to use and what kind of prints to use". Jasmine then continued on to emphasize that feedback's utility was driven by how well her friends and family understood her motivation to start her business:

"I think them knowing me and my passion behind wanting to do this project because they saw me go through [my fight with cancer] and they know my heart and desires to help other people at all times with anything...I think them knowing my passion for life and my zeal after my journey allowed them to kind of open their mind."

In reflecting on the benefits of her family providing feedback, Jasmine emphasized how a shared context between her and her personal relationships enabled her social audience to give helpful feedback. Therefore, when she took to her social media account to solicit feedback, such personal 
relations were able to provide ideas and assistance, in contrast to Tia who was met with confusion by those closest to them.

Another type of social audience which frequently arose in discussions was other small business owners: "We have a solid group of people who we seek feedback from who are in the community...it's a Facebook messenger chat, and there's eight people on it." -Emily. Haley described the benefits of a shared digital space with group members who could warn each other of how they may have "been down this road before" and could help them avoid common missteps (e.g., "don't ask this person for help" or "don't go this direction").

Asking for feedback from other small business owners on social media often preserved a shared context of common pitfalls, helpful resources, and the common understanding of the difficulties running a small business. However, when participants reflected on asking for feedback from their peers on social media, there were concerns about being judged or viewed as illegitimate for asking certain questions. Andrea, for instance, described the cut throat nature of filmmaking culture, and the implications to perceptions of their competency when feedback seeking from peers:

"In my industry, there's already a lot of judgment and competition. So it becomes like,

'Oh, this is what you're asking? You don't know what you're doing.' And then you're on the bad idiot lists."

For Andrea, asking for feedback from those in their community was synonymous to inherently admitting a lack of knowledge given the high levels of judgement in their discipline. Therefore, Andrea had to balance their requests for feedback with efforts to come across as competent in the eyes of those in their field. The risk was that of their reputation as a legitimate filmmaker. In addition to juggling perceptions of ability, Lisa reflected on how the "radical politics" in her field of beekeeping kept her on edge when interacting with other beekeepers: "I would call it the bipolarity of the farming, that it really is there." This worry to not inadvertently agitate her peers by challenging their political beliefs was ever present. And while Lisa's careful treading within her social groups was not directly tied to feedback seeking, Lisa nonetheless brought this up as she reflected on her process of asking for feedback from these groups.

\subsection{Seeking Feedback on Social Media When the Self and Business are Inseparable}

Across our discussions, participants reflected on the coupling between their identities and their businesses. This coupling was often so tight that participants regularly referred to themselves as a business, rather than an individual who runs a business (echoing themes from previous work on self-as-a-business [56].) For instance, Mia, who made jewelry and beauty products, reflected: "I run a business, but then myself, I'm also a business." This offline fusion of the self and the business manifested in online representations as well. For instance, Jessica illustrated how this sentiment affected her approach to social media, as she described having one social media account for both her personal connections and her business: "I just have one [social media] page, I did this for two reasons. One, it was made out of time management. I can't manage two accounts. Second, I want people to associate me with my brand. I feel like when I buy from other makers, I feel more connected when I know who they are and a little bit about them. I am more likely to engage with their posts. This is what I do, this is part of who I am." Alongside the efficiency benefits of merging her personal and business social media account, Jessica also highlighted the benefits of people understanding her business in relation to her own personal motivations. She found that this coupling of herself and her business led to more "authentic" relationships with her followers and increased engagement.

4.3.1 Authenticity and Opening Oneself Up While Seeking Feedback on Social Media. This tight coupling of the individual and the business, and the authentic relationship building with participants' followers which occurred on social media as a result, had important implications for seeking

Proc. ACM Hum.-Comput. Interact., Vol. 5, No. CSCW1, Article 15. Publication date: April 2021. 
feedback. If a feedback request was only business related, several participants suggested they could not expect to receive feedback. Revealing personal information, such as family members sporting products for sale, was something that participants described frequently doing, as a way to garner feedback by sparking engagement. For instance, Kristen noticed her feedback requests were almost entirely ignored in her private group of vetted customers, but when she asked for something "completely unrelated to her business", the responses poured in.

In the group discussion, participants reflected on how this fusion of themselves and their businesses was integral to the value proposition for building their businesses' online representation on social media, as opposed to just having a website or a profile on an online marketplace such as Etsy.com. Lisa explained how this tight fusion between herself and her business on social media implicated feedback seeking:

"The real engagement is in the brute process in that [product] evolution. I think that's something I need to learn to open up to myself...Social media can help you if you are open to that process evolving. It's not just that you're showing it, you're asking for feedback around the evolution of [the product]."

Here, Lisa described how her preferred social media platform enabled her to incorporate her follower's input into her creative process. Lisa noted this as what she perceived to be the deep-rooted value of social media for her small business: co-evolution of products with her social audience. In order to do so, Lisa noted the need to "open up" herself personally in order to take advantage of this value. Jessica also emphasized the importance of self-disclosure as a way to foster this co-evolution of products and build meaningful relationships. She hoped that her audience would reciprocate, making the sharing bi-directional: "There's a lot of benefits [to sharing]. It's about how we make friendships. I also want to know why [customers are] buying it, who it's for" In this way, Jessica expressed a desire to know her social media audience on a personal level as well.

Lola, who made accessories, and Lily, who made professional clothing, highlighted the importance of encouraging feedback and receiving support from their followers on social media. As Lola recounted, receiving feedback from others helped her with the final push to actually start her business: "One of the best feedback I've had is, because I'm such a critic of myself, I want it to be perfect, one of the greatest things someone said to me is: 'fust do it.'” By opening her business - and by extension herself - up to critique, Lola received not just a positive signal for business, but also the personal motivation needed in order to push forward. Lily, who struggled to make progress because of her self-described perfectionist tendencies was also fortunate to have a similarly positive experience when opening herself up to critique: "I was ego tripping with my business perfectionistic self, but once I let that weakness be seen, all the support and resources just poured in”. For Lily, Lola, Lisa, Jessica and others, the ability to build authentic relationships between small business owners and a diverse audience, by way of self-disclosure, was the unique value of seeking feedback on social media.

\subsubsection{Exposure, Discouragement, and Self-Regulation when Seeking Feedback on Social Media.}

Building a collaborative relationship around people and products looked different across participants. The main difference was rooted in the extent to which participants were comfortable with selfdisclosing on social media. When participants described making this decision, it seemed they were having a negotiation with themselves and sometimes their loved ones regarding privacy preferences. For instance, Jessica described how while she did not mind sharing information about her personal life, her partner and child felt differently:

"Part of me wishes I didn't have to think about what people might do with that information. Storytelling is really important to me. I don't mind sharing some of that. 
My husband does not like social media, doesn't use it. My oldest daughter who is a teen, she does not like things about herself being shared."

In addition to Jessica, Mary also paused before disclosing as she was worried disclosure could be interpreted as though she was fishing for compliments, and ultimately, that this would manifest inauthenticity. Mary acted out how she felt during a recent request: "'Here's my cute little painting. Do you like it? Do you like the colors? Does the composition work for you?' For me it always feels like I'm just begging for validation, but that's not quite it." While somewhat mocking herself, Mary felt discomfort by the implications of this fusion of self and business when seeking feedback, where she felt asking on social media for reactions to her paintings was equivalent to seeking personal validation.

Mary was not alone in her struggles to engage her audience in a way that was comfortable for her. These sorts of negotiations and relationship building processes were non-trivial when it came to involving such a diverse audience into one's process of making. For instance, Lisa explained how in order to welcome her social audience into her creative process, she needed to exude bravery: "It's really dynamic on social media when you're in the process of making, to allow people to be in that process with you [...] it takes bravery".

Due to the tight intermingling between the self and the business, receiving discouraging or conflicting feedback could trigger both personal and professional doubts. For instance, Lauren discussed how she had to ignore some feedback she received from those close to her in order to pursue her entrepreneurial endeavors:

"So many people told me, people I care about, told me: 'You're going to start a makerspace that is focused on women and equity? Like that sounds ridiculous. Nobody's going to use that.' I had to ignore that feedback."

When Lauren's small business proposition was met with discouragement, she took it as a personal question of her own competence and had to choose to ignore it in order to continue. Other participants' reflections also highlighted personal doubts in their own ability as a result of negative feedback. Sierra recalled grappling with "letting others project their fears onto you instead of keeping the optimistic frame of mind." Notably, Sierra described how receiving critical feedback was a reflection on her personhood, and not her business. The trepidation from seeking feedback and self-disclosing, when done simultaneously, coalesced and sometimes even compounded for participants.

Participants discussed needing to convince themselves of their own abilities and embarked on a process of self-regulation (i.e., becoming aware of one's concerns and then regulating them to persevere). For instance, Jessica described how when she first started her business, she struggled to believe in her ability to run a small business; even to the point where she struggled with impostor syndrome (i.e. the persistent inability to believe that one's success is deserved or has been legitimately achieved as a result of one's own efforts or skills [6]):

"I had to trust that I knew what I was doing. So for a first pattern, there's a lot of nerves with that and I told my friends I have impostor syndrome. I've been doing this for other people for years. I've never done it myself. Should I really be doing this? And yes, I should. I can do this. I did do it and it's gone very well."

Jessica experienced difficulty buttressing herself with the confidence and mental support to persevere.

Whether navigating critiques or positive encouragement, participants discussed needing to selfregulate to maintain balance and continue their work. Put together, the time invested in opening oneself up to a process of co-creation, regulating one's fluctuating feelings of worthiness, and doing so in a public-facing way often resulted in emotional fatigue. As Lisa, who earlier described the 
benefits of evolving her products with her audience on social media later, went on to articulate the exhaustion she felt:

"I think we're at this point with all the communication options we have right now that it is creating a high level of fatigue. That's what I noticed within me. I just have this feeling of overwhelm when it comes to engaging [on social media] because it's this huge other workflow...You have this emotional weight about feeling like you forgot to respond, or didn't respond."

To Lisa, the time spent on social media asking for, receiving, and managing feedback felt like entirely its own workflow. Specifically, she pointed to the "emotional weight" she felt when attempting to build relationships with her social groups. Determined to authentically include her social audience's inputs in her creative process, Lisa was often met with exasperation.

\section{LIMITATIONS}

This paper provides a detailed account of how 26 small business owners use social media to garner feedback on their product ideas and completed products. In particular, we focus our efforts on engaging communities that are frequently overlooked in the mainstream discussions of entrepreneurship, such as women. This is because women are more likely to be engaged in a side-hustle to make ends meet and leverage social media as part of this endeavor. Yet, to provide this level of depth, this paper sacrificed a breadth-level understanding of feedback seeking on social media. It should also be noted also that not everyone in our workshop consistently solicited feedback. Therefore, while prompts were aimed at opening discussion to past experience, for participants who had not recently solicited feedback, sentiments were hypothetical at times. Finally, the design workshop methodology comes with certain drawbacks, such as the likelihood for groupthink and performative responses. While the Think-Pair-Share approach remedies this in part, and participants did readily discuss vulnerabilities, this also represents a limitation.

\section{DISCUSSION}

\subsection{Informational Value of Large-Scale Feeds Outweighed by Need for Reliability}

Participants in our workshop were often involved in multiple lines of work and needed quick and reliable feedback. Though social media held the appeal of possessing large-scale, public communities of potential customers, the small business owners with whom we spoke did not find such large audiences accessible or even desirable for seeking feedback. They instead sought narrower, and often exclusive, audiences on social media platforms when soliciting feedback. Though larger audiences may well have more informational value, as posited by previous literature [18, 59], our results suggest that this informational value is less available to resource-constrained small business owners. Moreover, our findings suggest that investigating the measures participants put into place to overcome the inaccessibility of large, public feedback audiences may be a fruitful design opportunity.

6.1.1 Surfacing Hidden Feedback Behaviors. Previous work on online feedback exchange has investigated environments which were largely publicly accessible [36, 70, 75]. The methodologies used in such studies leverage observational approaches, such as web crawling large forums for publicly available data [70]. However, our findings suggest that much feedback-related data is not public, and so alternative methods may be required to unearth ongoing challenges to the success of feedback on social media. For instance, our participants actively worked to find or create exclusive spaces on social media when asking for feedback. Such activity might ordinarily go unnoticed by predominant methodological approaches. Therefore, future research in online feedback may 
further investigate and support these small, private groups through qualitative approaches such as interviews or diary studies.

\subsection{Shared Context and Trust are Crucial for Feedback to be Successful among Small Business Owners}

In our workshops, participants reflected on their experiences soliciting feedback on social media from a diverse audience composed of friends, family, peers, and potential customers. Interestingly, participants sought feedback from all types of audience members, and no type of audience stood out as distinctly more or less helpful than others. Rather, the small business owners in our workshop needed to trust their feedback providers to be respectful and nonjudgmental and keep their business or product ideas secure, as well as establish some type of shared context (such as the constraints of small business ownership).

6.2.1 Tensions Between the Benefits of Trustful and Anonymous Feedback Providers. Our findings call on the research community to move beyond interrogating static categories of feedback providers in terms of who might be most helpful for feedback (i.e., peers vs. crowd, friends vs. family, etc.) [75], and to instead examine the nature and quality of such relationships over time. For instance, online systems may also take into consideration the relationships between users in providing scaffolding for feedback exchanges. Feedback systems might be designed and deployed among those who have a trusting relationship, such as small business owners in the same geographic environment who may have known each other for some time. Such approaches might better leverage personal ties, a crucial ingredient for high quality feedback for creative practitioners, but one that is almost universally overlooked [53].

However, our findings also suggest caution for this future research direction. For the small businesses in our workshop, personal ties with feedback audience members indeed proved helpful. But this benefit was not universal and, in fact, personal connections could also be problematic in some ways. Participants worried about being dissuaded from following their dreams by people they cared about (in the case of Lauren and Tia), or worried about upsetting those close to them (in the case of Andrea and Lisa). Additionally, there were concerns around how personal relationships might influence feedback providers' ability to give critical feedback, with participants noting how feedback can sway positive and (at times) superficial when solely shared among personal relationships.

Prior work considers anonymity as one way to meet these challenges. For instance, Hui et al. have investigated how preserving anonymity between feedback seeker and feedback provider can influence the quality of feedback offered, and that feedback providers were more likely to give critical feedback when they could maintain their anonymity [34]. Other work has leveraged an anonymous, non-expert crowd to provide design practitioners with rapid feedback [71]. However, participants in our workshops did not seek anonymous feedback. Indeed, our participants actively worked to find others who they knew (in the case of Tia, Andrea, Haley, Lily, Lola, and Sarah) and could trust to keep their work-in-progress ideas safe (in the case of Kim, Tia, Emily, and Sierra). While preserving anonymity may work well in a classroom or organizational context, the small business owners with whom we spoke actively worked to seek feedback from those with which they had an existing relationship. Participants needed to know who was giving feedback to ensure their ideas and reputation, and by extension their income, were safeguarded. In short, for the small business owners in our workshop, anonymity was not desirable because the stakes were high: their feedback seeking was tied directly to their livelihoods.

How might future work combine the benefits of high-quality critical feedback from anonymous audiences, with the benefits of trust that our participants worked to create? One opportunity

Proc. ACM Hum.-Comput. Interact., Vol. 5, No. CSCW1, Article 15. Publication date: April 2021. 
might be in developing interventions which support generation of both positive and critical feedback among those with trusting relationships by, for instance, combining critical feedback with encouragement and self-affirmation (using techniques such as "wise feedback") [73].

A trustful relationship was not the only aspect of participants found beneficial when determining who in their social audience would provide helpful feedback. In the next section, we discuss how participants also benefited from a shared context with their feedback providers.

6.2.2 Supporting a Shared Context for Small Businesses Seeking Feedback on Social Media. Participants reduced the chances of receiving feedback which was off topic, out of scope, or too critical and discouraging by seeking a shared context with the person giving feedback. This shared context communicated aspects of their feedback request that participants did not know how-or did not want-to articulate in their request for feedback. For example, audiences with shared contexts understood the common challenges of small business ownership, the difficulties of self-regulating when receiving critical feedback, and how personal motivations and stories supported their business pursuits.

Research on feedback seeking in online communities has focused on sites like weBOOK, Dribbble, Flickr which provide an inherent shared context, for example, by uniting individuals who share a creative medium [23]. This shared context often encapsulates the invisible parts of a solicitation such as motivation or intended goal [31]. While social media sites have much more heterogeneity, small business owners found ways to push beyond this context collapse [54]. For instance, the small business owners in our workshop found ways to reinstate a shared context with audience targeting when soliciting feedback. Future research could focus on creating tools that systematize the formation of shared contexts while retaining the trusting relationships common in small social media groups [51].

One opportunity to create shared contexts is to support facilitating online feedback among reciprocal peers groups, where a shared context-for instance, of small business ownership-is likely to exist. Online peer groups offer unique value for seeking feedback as a way of encouraging reciprocity even at scale [44], which is critical for online community sustainability [43]. In addition, prior work suggests that peers may occupy a "Goldilocks" zone of context, where they have sufficient shared context to be helpful, but not so much that they fail to see flaws [12]. This level of shared context helps peers more accurately identify successful work earlier on in a design process, as compared to self-evaluation [12]. Given this utility of peers, several tools exist to support peer feedback on open-ended work, specifically for university students of design [69] and entrepreneurship [34]. For instance, one system enabled students in an in-person design course to include examples when giving peers feedback [37]. Another tool leveraged the scale of large, in-person classes to provide student peers with rapid feedback on their ideas [45]. However, these approaches are designed for deployment within a classroom setting, where users are not immediately financially tied to outcomes as small business owners are to their work. With this in mind, these approaches would likely need to be adapted to be useful in contexts similar to the ones our small business owners described.

\subsection{The Additional Labor of Seeking Feedback on Social Media}

Social media can be a powerful tool to enhance one's business presence, engage with potential customers, and build an invested community [20]. At the same time, the stories of small business owners captured in this paper shed light on how challenging it can be to leverage social media to tap into the benefits of product co-creation. Recall the tension that Lisa pointed to between leveraging the value of building authentic engagement through involving her audience in the process of creating and the "emotional weight" such an endeavor sparked. Sociologist Arlie Hoschschild 
calls this "self-modulation" in her inquiry of those aspiring to commercialize their social media pursuits [32]. Such self-modulation refers to the social psychological concept of self-regulation: becoming aware of one's own concerns and then regulating one's concerns with the goal of improving and persevering [79]. The self-regulation exhibited by participants can be viewed through the lens of emotional labor, or labor that "requires one to induce or suppress feeling in order to sustain the outward countenance that produces the proper state of mind in others" [32]. For example, recall Jessica's negotiation with fear around disclosing personal information and not allowing herself to think of potential bad consequences. Given our focus on women small business owners in this paper, we surface this theme to shed light on this less visible part of feedback seeking on social media and note that emotional labor is often, although not always, found in work typically performed by women.

Hui et al. discuss how managing social media accounts is "additional labor" that entrepreneurs must take on to be successful in their "self-entrepreneur-izing" endeavors [11]. In using this term, they refer to labor which goes unobserved and unsupported by official programs meant to support these individuals. This paper presents another perspective to social media use for those attempting to self-entrepreneurial-ize. Specifically, it highlights the work participants needed to perform to self-regulate inner reactions when asking for feedback given the tight coupling between themselves and their business and describes in greater detail the specific kinds of additional labor necessary for using social media. For instance, throughout the workshops, there were moments when participants reflected on the self-regulation involved when soliciting feedback on social media, and how this was an "additional workflow" in itself. This is consistent with prior work that describes how the process of design elicits an emotional investment in one's work, and how this investment in turns fosters a sense of identity [80]. The product design community often encourages such an investment [26]; our work highlights how such investments may lead to additional labor for small business owners when seeking feedback.

6.3.1 Balancing the Personal and the Professional. Given the personal investment of small business owners in their creations, participants in our workshop also shed light on the pressure they felt to disclose personal information to both personal and business networks in order to engage their audience and successfully garner feedback. Such self-disclosure-the process of intentionally revealing personal information [28]-can help to strengthen interpersonal relationships, which can in turn foster a sense of community between small business owners and their audience. Yet, many participants were hesitant to further blur the boundary between their personal life and their business on social media. This hesitation reflected not only participants' personal preferences, but often also those of family members (recall Jessica's teenage daughter uninterested in modeling her mother's designs).

Existing literature on the affordances of co-creation in social commerce reflects optimistic views of the unique value social media provides for businesses-large businesses [60] with entire teams dedicated to "social". When highlighting the challenges for small business owners to do the same, we consider a potential oversight warranting future discussion. That is, in addition to simply having more resources and personnel, large businesses can also leverage an important division of labor in order to ask for feedback effectively on social media [66]. For instance, workplace teams dedicated to "social" ask for, synthesize, and hand over resulting suggestions from social media to the different teams within the organization who in turn build products. In contrast, for the small business owners in our workshop, both roles of feedback solicitor and product creator were embodied in the same entity, one individual. To make our themes on the unique challenges of small business owners asking for feedback on social media more salient, we draw attention to the compounding effects such challenges often impose. For example, imagine asking for feedback from 
an uncertain audience, being unsure if requests were seen, opening oneself up to potential critique from all facets of one's life-all of this as a part of a highly personal endeavor which, for many, will continue to grow in financial importance. Future work addressing these challenges will make fundamental advances in methods for seeking feedback, as well as have a substantial impact on the lives of minority small business owners.

6.3.2 Balancing Reputational and Psychological Risks When Seeking Early-Stage Feedback. Our participants also highlighted the tension between self-presentation and seeking effective feedback, especially formative feedback (i.e., feedback on early-stage ideas or incomplete products). While participants were well aware of this challenge, they did not know how to address it. The feedback research community has thoroughly attempted to address this issue, for instance, by creating environments where creative practitioners only share in-progress work and reduce comparisons to finished work [39]. However, for small businesses seeking feedback on social media, this partitioning seemed counterintuitive to the value of feedback on social media. That is, participants desired the access to diverse audiences and the various broadcast levels accessible on social media These perspectives suggest a need to devise a solution that is more integrated into the existing daily practices of small business owners and their desire to manage their professional identity among customers. Therefore, future work could explore balancing formative feedback seeking with maintaining professionality-for instance by reminding feedback audience members that an artifact is a work-in-progress and to judge it accordingly. In addition, research may consider how small and exclusive groups help to mitigate additional labors for small business owners when seeking feedback, such as fretting over whether feedback requests are engaging enough to be picked up by algorithmically controlled feeds, explaining the context small business constraints, worrying about stolen ideas, and the apprehension of opening oneself up to critique.

Similarly, our results suggest a resolution to an apparent paradox: while large companies and professional designers seek feedback on unfinished products, small business owners who in theory would benefit more from feedback are reluctant to do so [41]. While such resistance may seem to be not aligned with best practice [67], some small business owners we met described how such a request was synonymous with admitting a lack of knowledge, and others felt it would make them seem self-aggrandizing. The lower the fidelity of the artifact (i.e., the earlier on in their creation process), the larger these threats became. In contrast, larger companies have credibility already built into a brand [25], and there is less reputational cost for seeking formative feedback. Taken together, our findings suggest that environments built to encourage early feedback among independent creators (e.g. [5,39]) may implicitly be designed for creators at larger companies with fewer reputational threats. Our findings also offer clues for why these tools (e.g. [5, 39]) and their underlying design processes may continue to struggle with adoption among small business owners. In addition, our findings suggest that considering the psychological and reputational issues small business owners face may be key to designing more widely applicable work-in-progress feedback environments.

\section{CONCLUSION}

Drawing on a series of design workshops and interviews with 26 small business owners at a local feminist makerspace, this paper reports on the challenges minority small business owners experienced when seeking feedback on open-ended work (e.g. product design) via social media. From these empirical engagements, we found that feedback seeking from large-scale audiences was neither accessible nor desirable, as doing so often meant receiving responses from unknown individuals and brought work of deliberation (e.g., verifying the genuineness of the advice). Seeking feedback in large-scale settings also meant participant's requests competed with social life updates and general 
business promotion, making it hard for others to view the request (due to algorithmically-controlled feeds). To overcome these challenges, small business owners narrowly targeted specific audiences (via direct message channels and private groups) in order to reliably seek feedback on social media platforms. Determining the composition of these small groups proved non-trivial, and each audience type-personal connection, competitor, and collaborator-had different background knowledge and motivation for engaging with feedback requests. Business owners described succeeding with feedback seeking only when there was both shared context (e.g., feedback givers ran a small business themselves, understood their personal motivations) and a trusting relationship (e.g., to keep ideas safe).

Additionally, participants reflected on the tight coupling between their identities and their businesses-often so tight that participants regularly referred to themselves as a business-and this had implications for feedback seeking. For instance, participants struggled to incorporate their social media followers' feedback while simultaneously not internalizing discouragement. Such endeavors required protecting one's time, energy, and motivation through self-regulation in order to build authentic relationships with followers and maintain creative momentum.

We situate these findings in the context that participants were often sole proprietors, juggled multiple lines of work and tried to make ends meet through the commercialization of their creative work. Our findings suggest that, for small business owners who resource-constrained, fruitful feedback relationships are with small audiences and push beyond static categories of peers, friends, or family. This work highlights the need to examine the dynamic nature of feedback seeker and giver relationships over time, such as how trust may shift as relationships develop or fragment. Finally, our findings offer a detailed illustration of the arduous self-regulation practices required of small business owners participating in feedback exchange on social media, particularly given the tight interplay between the self and the business.

\section{ACKNOWLEDGEMENTS}

We thank all staff members of Prototype PGH for their support in conducting the design workshops, especially Erin Gatz. We also thank our workshop and interview participants for their thoughtful and frank reflections, and we thank our paper reviewers for their suggestions. This research was conducted under Carnegie Mellon's IRB protocol \#STUDY2019_00000316 and was funded in part by Facebook, Inc.

\section{REFERENCES}

[1] [n.d.]. Etys 2017 Impact Report. https://extfiles.etsy.com/Impact/2017EtsyImpactUpdate.pdf. Accessed: 2020-01-23.

[2] [n.d.]. Etys 2018 Transparency Report. https://extfiles.etsy.com/advocacy/Etsy_2018_Transparency_Report.pdf. Accessed: 2019-10-12.

[3] [n.d.]. Etys 2019 Transparency Report. https://extfiles.etsy.com/advocacy/Etsy_2019_Transparency_Report.pdf. Accessed: 2020-05-12.

[4] [n.d.]. Forever 21's design features a slightly different "I" but is otherwise basically identical to Larson's. https: //www.buzzfeed.com/stephaniemcneal/forever-21-design-claims. Accessed: 2019-10-12.

[5] [n.d.]. The Future Of Work In Progress (WIPs). https://web.archive.org/web/20160421001929/https://help.behance.net/ hc/en-us/articles/218288227-The-future-of-Work-in-Progress-WIPs-. Accessed: 2019-10-12.

[6] [n.d.]. Impostor Syndrome: A definition. https://www.lexico.com/en/definition/impostor_syndrome. Accessed: 2019-10-12.

[7] [n.d.]. Survey: Nearly 1 in 3 side hustlers needs the income to stay afloat. https://www.bankrate.com/personalfinance/side-hustles-survey-june-2019/. Accessed: 2020-05-20.

[8] [n.d.]. Treating regular people like influencers is the key to Glossier's success. https://www.vox.com/the-goods/2019/ 1/15/18184151/glossier-emily-weiss-marketing-strategy-recode. Accessed: 2020-05-20.

[9] Place. Prototype PGH. https://prototypepgh.com/.

[10] Susan J Ashford and Larry L Cummings. 1983. Feedback as an individual resource: Personal strategies of creating information. Organizational behavior and human performance 32, 3 (1983), 370-398. 
[11] Seyram Avle, Julie Hui, Silvia Lindtner, and Tawanna Dillahunt. 2019. Additional Labors of the Entrepreneurial Self. Proceedings of the ACM on Human-Computer Interaction 3, CSCW (2019), 1-24.

[12] Justin M Berg. 2016. Balancing on the creative highwire: Forecasting the success of novel ideas in organizations. Administrative Science Quarterly 61, 3 (2016), 433-468.

[13] Moira Burke, Robert Kraut, and Cameron Marlow. 2011. Social capital on Facebook: Differentiating uses and users. In Proceedings of the SIGCHI conference on human factors in computing systems. 571-580.

[14] Bill Buxton. 2010. Sketching user experiences: getting the design right and the right design. Morgan kaufmann.

[15] Mariko Lin Chang. 2010. Shortchanged: Why women have less wealth and what can be done about it. Oxford University Press.

[16] Kathy Charmaz and Linda Liska Belgrave. 2007. Grounded theory. The Blackwell encyclopedia of sociology (2007)

[17] Ruijia Cheng, Ziwen Zeng, Maysnow Liu, and Steven Dow. 2020. Critique Me: Exploring How Creators Publicly Request Feedback in an Online Critique Community. Proceedings of the ACM on Human-Computer Interaction 4, CSCW2 (2020), 1-24.

[18] Patrick A Crain and Brian P Bailey. 2017. Share Once or Share Often?: Exploring How Designers Approach Iteration in a Large Online Community. In Proceedings of the 2017 ACM SIGCHI Conference on Creativity and Cognition. ACM, 80-92.

[19] Tawanna R Dillahunt and Joey Chiao-Yin Hsiao. 2020. Positive Feedback and Self-reflection: Features to Support Self-efficacy among Underrepresented Job Seekers. In Proceedings of the 2020 CHI Conference on Human Factors in Computing Systems. 1-13.

[20] Brooke Erin Duffy. 2017. (Not) getting paid to do what you love: Gender, social media, and aspirational work. Yale University Press.

[21] Nicole Ellison, Rebecca Gray, Jessica Vitak, Cliff Lampe, and Andrew T Fiore. 2013. Calling all Facebook friends: Exploring requests for help on Facebook. In Seventh international AAAI conference on Weblogs and social media.

[22] Brynn M Evans, Sanjay Kairam, and Peter Pirolli. 2010. Do your friends make you smarter?: An analysis of social strategies in online information seeking. Information Processing \& Management 46, 6 (2010), 679-692.

[23] Eureka Foong, Steven P Dow, Brian P Bailey, and Elizabeth M Gerber. 2017. Online feedback exchange: A framework for understanding the socio-psychological factors. In Proceedings of the 2017 CHI Conference on Human Factors in Computing Systems. ACM, 4454-4467.

[24] Sarah Fox, Rachel Rose Ulgado, and Daniela Rosner. 2015. Hacking culture, not devices: Access and recognition in feminist hackerspaces. In Proceedings of the 18th ACM conference on Computer supported cooperative work \& social computing. ACM, 56-68.

[25] Johann Füller, Kurt Matzler, and Melanie Hoppe. 2008. Brand community members as a source of innovation. Fournal of Product Innovation Management 25, 6 (2008), 608-619.

[26] Pascalle CM Govers and Ruth Mugge. 2004. I love my Jeep, because its tough like me: The effect of product-personality congruence on product attachment. In Proceedings of the fourth international conference on design and emotion, Ankara, Turkey. 12-14.

[27] Mary L Gray and Siddharth Suri. 2019. Ghost Work: How to Stop Silicon Valley from Building a New Global Underclass. Eamon Dolan Books.

[28] Kathryn Greene, Valerian J Derlega, and Alicia Mathews. 2006. Self-disclosure in personal relationships. The Cambridge handbook of personal relationships (2006), 409-427.

[29] F Maxwell Harper, Daphne Raban, Sheizaf Rafaeli, and Joseph A Konstan. 2008. Predictors of answer quality in online Q\&A sites. In Proceedings of the SIGCHI Conference on Human Factors in Computing Systems. 865-874.

[30] Christina N Harrington, Katya Borgos-Rodriguez, and Anne Marie Piper. 2019. Engaging Low-Income African American Older Adults in Health Discussions through Community-based Design Workshops. In Proceedings of the 2019 CHI Conference on Human Factors in Computing Systems. ACM, 593.

[31] John Hattie and Helen Timperley. 2007. The power of feedback. Review of educational research 77, 1 (2007), 81-112.

[32] Arlie Russell Hochschild. 2012. The managed heart: Commercialization of human feeling. Univ of California Press.

[33] Julie Hui, Nefer Ra Barber, Wendy Casey, Suzanne Cleage, Danny C Dolley, Frances Worthy, Kentaro Toyama, and Tawanna R Dillahunt. 2020. Community Collectives: Low-tech Social Support for Digitally-Engaged Entrepreneurship. In Proceedings of the 2020 CHI Conference on Human Factors in Computing Systems. 1-15.

[34] Julie Hui, Amos Glenn, Rachel Jue, Elizabeth Gerber, and Steven Dow. 2015. Using anonymity and communal efforts to improve quality of crowdsourced feedback. In Third AAAI Conference on Human Computation and Crowdsourcing.

[35] Julie Hui, Kentaro Toyama, Joyojeet Pal, and Tawanna Dillahunt. 2018. Making a Living My Way: Necessity-driven Entrepreneurship in Resource-Constrained Communities. Proceedings of the ACM on Human-Computer Interaction 2 , CSCW (2018), 71.

[36] Julie S Hui, Elizabeth M Gerber, and Steven P Dow. 2014. Crowd-based design activities: helping students connect with users online. In Proceedings of the 2014 conference on Designing interactive systems. ACM, 875-884. 
[37] Hyeonsu B Kang, Gabriel Amoako, Neil Sengupta, and Steven P Dow. 2018. Paragon: An online gallery for enhancing design feedback with visual examples. In Proceedings of the 2018 CHI Conference on Human Factors in Computing Systems. 1-13.

[38] Tom Kelley and David Kelley. 2013. Creative confidence: Unleashing the creative potential within us all. Currency.

[39] Joy Kim, Maneesh Agrawala, and Michael S Bernstein. 2017. Mosaic: designing online creative communities for sharing works-in-progress. In Proceedings of the 2017 ACM Conference on Computer Supported Cooperative Work and Social Computing. ACM, 246-258.

[40] Avraham N Kluger and Angelo DeNisi. 1996. The effects of feedback interventions on performance: A historical review, a meta-analysis, and a preliminary feedback intervention theory. Psychological bulletin 119, 2 (1996), 254.

[41] Yasmine Kotturi and McKayla Kingston. 2019. Why do Designers in the "Wild" Wait to Seek Feedback Until Later in their Design Process?. In Proceedings of the 2019 on Creativity and Cognition. ACM, 541-546.

[42] Markus Krause, Tom Garncarz, JiaoJiao Song, Elizabeth M Gerber, Brian P Bailey, and Steven P Dow. 2017. Critique style guide: Improving crowdsourced design feedback with a natural language model. In Proceedings of the $2017 \mathrm{CHI}$ Conference on Human Factors in Computing Systems. ACM, 4627-4639.

[43] Robert E Kraut and Paul Resnick. 2012. Building successful online communities: Evidence-based social design. Mit Press.

[44] Chinmay Kulkarni, Koh Pang Wei, Huy Le, Daniel Chia, Kathryn Papadopoulos, Justin Cheng, Daphne Koller, and Scott R Klemmer. 2013. Peer and self assessment in massive online classes. ACM Transactions on Computer-Human Interaction (TOCHI) 20, 6 (2013), 33.

[45] Chinmay E Kulkarni, Michael S Bernstein, and Scott R Klemmer. 2015. PeerStudio: rapid peer feedback emphasizes revision and improves performance. In Proceedings of the second (2015) ACM conference on learning@ scale. ACM, $75-84$.

[46] Stacey Kuznetsov and Eric Paulos. 2010. Rise of the expert amateur: DIY projects, communities, and cultures. In Proceedings of the 6th Nordic Conference on Human-Computer Interaction: Extending Boundaries. ACM, 295-304.

[47] Lan Li, Xiongyi Liu, and Allen L Steckelberg. 2010. Assessor or assessee: How student learning improves by giving and receiving peer feedback. British journal of educational technology 41, 3 (2010), 525-536.

[48] Kurt Luther, Amy Pavel, Wei Wu, Jari-lee Tolentino, Maneesh Agrawala, Björn Hartmann, and Steven P Dow. 2014 CrowdCrit: crowdsourcing and aggregating visual design critique. In Proceedings of the companion publication of the 17th ACM conference on Computer supported cooperative work \& social computing. 21-24.

[49] Kurt Luther, Jari-Lee Tolentino, Wei Wu, Amy Pavel, Brian P Bailey, Maneesh Agrawala, Björn Hartmann, and Steven P Dow. 2015. Structuring, aggregating, and evaluating crowdsourced design critique. In Proceedings of the 18th ACM Conference on Computer Supported Cooperative Work \& Social Computing. ACM, 473-485.

[50] Frank Lyman. 1987. Think-pair-share: An expanding teaching technique. Maa-Cie Cooperative News 1, 1 (1987), 1-2.

[51] Xiao Ma, Justin Cheng, Shankar Iyer, and Mor Naaman. 2019. When Do People Trust Their Social Groups?. In Proceedings of the 2019 CHI Conference on Human Factors in Computing Systems. ACM, 67.

[52] Lena Mamykina, Bella Manoim, Manas Mittal, George Hripcsak, and Björn Hartmann. 2011. Design lessons from the fastest q\&a site in the west. In Proceedings of the SIGCHI conference on Human factors in computing systems. ACM, 2857-2866.

[53] Jennifer Marlow and Laura Dabbish. 2014. From rookie to all-star: professional development in a graphic design social networking site. In Proceedings of the 17th ACM conference on Computer supported cooperative work \& social computing. ACM, 922-933.

[54] Alice E Marwick and Danah Boyd. 2011. I tweet honestly, I tweet passionately: Twitter users, context collapse, and the imagined audience. New media \& society 13, 1 (2011), 114-133.

[55] Meredith Ringel Morris, Jaime Teevan, and Katrina Panovich. 2010. What do people ask their social networks, and why?: a survey study of status message q\&a behavior. In Proceedings of the SIGCHI conference on Human factors in computing systems. ACM, 1739-1748.

[56] Gina Neff. 2012. Venture labor: Work and the burden of risk in innovative industries. MIT press.

[57] Thi Thao Duyen T Nguyen, Thomas Garncarz, Felicia Ng, Laura A Dabbish, and Steven P Dow. 2017. Fruitful Feedback: Positive affective language and source anonymity improve critique reception and work outcomes. In Proceedings of the 2017 ACM Conference on Computer Supported Cooperative Work and Social Computing. ACM, 1024-1034.

[58] David J Nicol and Debra Macfarlane-Dick. 2006. Formative assessment and self-regulated learning: A model and seven principles of good feedback practice. Studies in higher education 31, 2 (2006), 199-218.

[59] Anne Oeldorf-Hirsch and Darren Gergle. 2020. 'Who Knows What' Audience Targeting for Question Asking on Facebook. Proceedings of the ACM on Human-Computer Interaction 4, GROUP (2020), 1-20.

[60] Frank T Piller, Alexander Vossen, and Christoph Ihl. 2012. From social media to social product development: the impact of social media on co-creation of innovation. Die Unternehmung 65, 1 (2012).

[61] Ayala Malach Pines, Miri Lerner, and Dafna Schwartz. 2010. Gender differences in entrepreneurship. Equality, diversity and inclusion: An International journal 29, 2 (2010), 186-198.

Proc. ACM Hum.-Comput. Interact., Vol. 5, No. CSCW1, Article 15. Publication date: April 2021. 
[62] Daniela K Rosner, Saba Kawas, Wenqi Li, Nicole Tilly, and Yi-Chen Sung. 2016. Out of time, out of place: Reflections on design workshops as a research method. In Proceedings of the 19th ACM Conference on Computer-Supported Cooperative Work \& Social Computing. ACM, 1131-1141.

[63] Ari Schlesinger, W Keith Edwards, and Rebecca E Grinter. 2017. Intersectional HCI: Engaging identity through gender, race, and class. In Proceedings of the 2017 CHI Conference on Human Factors in Computing Systems. ACM, 5412-5427.

[64] Donald Schön. 1983. The reflective practitioner. How professionals think in action. London: Temple Smith (1983).

[65] Clay Spinuzzi. 2005. The methodology of participatory design. Technical communication 52, 2 (2005), 163-174.

[66] Anselm Strauss. 1985. Work and the division of labor. Sociological quarterly 26, 1 (1985), 1-19.

[67] Maryam Tohidi, William Buxton, Ronald Baecker, and Abigail Sellen. 2006. Getting the right design and the design right. In Proceedings of the SIGCHI conference on Human Factors in computing systems. ACM, 1243-1252.

[68] Cristen Torrey, Elizabeth F Churchill, and David W McDonald. 2009. Learning how: the search for craft knowledge on the internet. In Proceedings of the SIGCHI Conference on Human Factors in Computing Systems. ACM, 1371-1380.

[69] Helen Wauck, Yu-Chun Yen, Wai-Tat Fu, Elizabeth Gerber, Steven P Dow, and Brian P Bailey. 2017. From in the class or in the wild? Peers provide better design feedback than external crowds. In Proceedings of the 2017 CHI Conference on Human Factors in Computing Systems. 5580-5591.

[70] Anbang Xu and Brian Bailey. 2012. What do you think?: a case study of benefit, expectation, and interaction in a large online critique community. In Proceedings of the ACM 2012 conference on Computer Supported Cooperative Work. ACM, 295-304.

[71] Anbang Xu, Shih-Wen Huang, and Brian Bailey. 2014. Voyant: generating structured feedback on visual designs using a crowd of non-experts. In Proceedings of the 17th ACM conference on Computer supported cooperative work \& social computing. 1433-1444.

[72] Anbang Xu, Huaming Rao, Steven P Dow, and Brian P Bailey. 2015. A classroom study of using crowd feedback in the iterative design process. In Proceedings of the 18th ACM conference on computer supported cooperative work \& social computing. ACM, 1637-1648.

[73] David Scott Yeager, Valerie Purdie-Vaughns, Julio Garcia, Nancy Apfel, Patti Brzustoski, Allison Master, William T Hessert, Matthew E Williams, and Geoffrey L Cohen. 2014. Breaking the cycle of mistrust: Wise interventions to provide critical feedback across the racial divide. Journal of Experimental Psychology: General 143, 2 (2014), 804.

[74] Yu-Chun Yen. 2017. Enhancing the Usage of Crowd Feedback for Iterative Design. In Proceedings of the 2017 ACM SIGCHI Conference on Creativity and Cognition. 513-517.

[75] Yu-Chun Grace Yen, Steven P Dow, Elizabeth Gerber, and Brian P Bailey. 2016. Social Network, Web Forum, or Task Market?: Comparing Different Crowd Genres for Design Feedback Exchange. In Proceedings of the 2016 ACM Conference on Designing Interactive Systems. ACM, 773-784.

[76] Yu-Chun Grace Yen, Steven P Dow, Elizabeth Gerber, and Brian P Bailey. 2017. Listen to others, listen to yourself: Combining feedback review and reflection to improve iterative design. In Proceedings of the 2017 ACM SIGCHI Conference on Creativity and Cognition. 158-170.

[77] Haiyi Zhu, Robert Kraut, and Aniket Kittur. 2012. Effectiveness of shared leadership in online communities. In Proceedings of the ACM 2012 conference on Computer Supported Cooperative Work. 407-416.

[78] Haiyi Zhu, Amy Zhang, Jiping He, Robert E Kraut, and Aniket Kittur. 2013. Effects of peer feedback on contribution: a field experiment in Wikipedia. In Proceedings of the SIGCHI Conference on Human Factors in Computing Systems. 2253-2262.

[79] Barry J Zimmerman. 2000. Attaining self-regulation: A social cognitive perspective. In Handbook of self-regulation. Elsevier, 13-39.

[80] John Zimmerman. 2009. Designing for the self: making products that help people become the person they desire to be. In Proceedings of the SIGCHI Conference on Human Factors in Computing Systems. ACM, 395-404.

Received June 2020; revised October 2020; accepted December 2020 